\title{
Does vitamin D status contribute to caveolin-1-mediated insulin sensitivity in skeletal muscle?
}

\author{
B. J. Boucher
}

Received: 9 June 2009 / Accepted: 24 June 2009/Published online: 12 August 2009

(C) Springer-Verlag 2009

To the Editor: As originally postulated by Harold Himsworth [1], a reduction in insulin sensitivity in muscle is associated with an increased risk of human type 2 diabetes. Thus, the finding that downregulation of caveolin-1 production leads to a reduction in insulin resistance, which is improved by upregulation of production of this protein as described by $\mathrm{Oh}$ et al. [2], is of considerable interest. Appropriate modulation of caveolin-1 production might be expected to be of benefit for reduction of the risk of type 2 diabetes in humans.

Hypovitaminosis $\mathrm{D}$ has been shown to be associated 'dose-wise' with lower insulin sensitivity in humans in cross-sectional studies [3, 4]; it is also associated with an increased risk of type 2 diabetes both cross-sectionally and prospectively in humans [5-7]. Caveolin-1 protein is necessary for the rapid non-genomic actions of activated vitamin D [8]. Adequate vitamin D repletion may contribute, therefore, to the maintenance of insulin sensitivity in humans through caveolin-1 modulation. This possibility is supported by the finding of marked insulin resistance and vitamin D resistance in humans with Berardinelli-Seip congenital lipodystrophy, who have a homozygous nonsense caveolin-1 mutation [9]. It would, therefore, be of great interest to know whether activated vitamin D improves insulin sensitivity in the JYD mouse (an ageingdependent non-obese animal model of type 2 diabetes) of

B. J. Boucher $(\bowtie)$

Centre for Diabetes \& Metabolic Medicine, Bart's \& The London Queen Mary's School of Medicine \& Dentistry,

2 Newark Street,

London E1 2AT, UK

e-mail: bboucher@doctors.org.uk
Oh et al. [2] and, if so, whether this might be caused by upregulation of caveolin-1 production.

Duality of interest The author states that there is no duality of interest associated with this manuscript.

\section{References}

1. Himsworth HP (1949) The syndrome of diabetes mellitus and its causes. Lancet 19:465-473

2. Oh YS, Khil L-Y, Cho KA et al (2008) A potential role for skeletal muscle caveolin-1 as an insulin sensitivity modulator in ageingdependent non-obese type 2 diabetes: studies in a new mouse model. Diabetologia 51:1025-1034

3. Baynes KC, Boucher BJ, Feskens EJ, Kromhout D (1997) Vitamin $\mathrm{D}$, glucose tolerance and insulinaemia in elderly men. Diabetologia 40:344-347

4. Chiu KC, Chu A, Go VL, Saad MF (2004) Hypovitaminosis D is associated with insulin resistance and beta cell dysfunction. Am J Clin Nutr 79:820-825

5. Hyppönen E, Boucher BJ, Berry DJ, Power C (2008) 25 hydroxyvitamin D, IGF-1 and metabolic syndrome at 45 years of age: a cross-sectional study in the 1958 British Birth Cohort. Diabetes 57:298-305

6. Forouhi NG, Luan J, Cooper A et al (2008) Baseline serum 25hydroxyvitamin D is predictive of future glycaemic status and insulin resistance: the Medical Research Council Ely Prospective Study 1990-2000. Diabetes 57:2619-2625

7. Knekt P, Laaksonen M, Mattila C et al (2008) Serum vitamin D and subsequent occurrence of type 2 diabetes. Epidemiology 19:666671

8. Huhtakangas JA, Olivera CJ, Bishop JE et al (2004) The vitamin D receptor is present in caveolae-enriched plasma membranes and binds 1 alpha, 25(OH)2-vitamin D3 in vivo and in vitro. Mol Endocrinol 18:2660-2671

9. Kim CA, Delépine M, Boutet E et al (2008) Association of a homozygous nonsense caveolin-1 mutation with Berardinelli-Seip congenital lipodystrophy. J Clin Endocrinol Metab 93:1129-1134 